\title{
CAH to CAH
}

\section{EHR Implementation Advice to Critical Access Hospitals from Peer Experts and Other Key Informants}

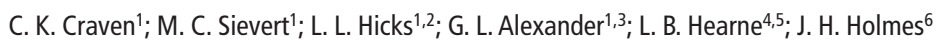

${ }^{1} \mathrm{MU}$ Informatics Institute, University of Missouri, Columbia, Missouri; ${ }^{2}$ Department of Health Management and Informatics, School of Medicine, University of Missouri, Columbia, Missouri; ${ }^{3}$ Sinclair School of Nursing, University of Missouri, Columbia, Missouri; ${ }^{4}$ Department of Statistics, University of Missouri, Columbia, Missouri; ${ }^{5}$ Bond Life Sciences Center, University of Missouri,

Columbia, Missouri; ${ }^{6}$ Department of Biostatistics \& Epidemiology, Perelman School of Medicine, University of Pennsylvania, Philadelphia, Pennsylvania

\section{Keywords}

Electronic health records, rural hospitals, critical access hospitals, qualitative research, medical informatics.

\section{Summary}

The US government allocated $\$ 30$ billion to implement electronic health records (EHRs) in hospitals and provider practices through policy addressing Meaningful Use (MU). Most small, rural hospitals, particularly those designated as Critical Access Hospitals (CAHs), comprising nearly a quarter of US hospitals, had not implemented EHRs before. Little is known about implementation in this setting. Socio-technical factors differ between larger hospitals and CAHs, which continue to lag behind other hospitals in EHR adoption.

Objectives: The main objective is to provide EHR implementation advice for CAHs from a spectrum of experts with an emphasis on recommendations from their peers at CAHs that have undertaken the process. The secondary objective is to begin to identify implementation process differences at CAHs v. larger hospitals.

Methods: We interviewed 41 experts, including 16 CAH staff members from EHR teams at 10 CAHs that recently implemented EHRs. We qualitatively analyzed the interviews to ascertain themes and implementation recommendations.

Results: Nineteen themes emerged. Under each theme, comments by experts provide in-depth advice on all implementation stages including ongoing optimization and use. We present comments for three top themes as ranked by number of CAH peer experts commenting - EHR System Selection, EHR Team, and Preparatory Work - and for two others, Outside Partners/Resources and Clinical Decision Support (CDS)/Knowledge Management (KM). Comments for remaining themes are included in tables.

Discussion: CAH experts rank the themes differently from all experts, a likely indication of the differences between hospitals. Comments for each theme indicate the specific difficulties CAHs encountered. CAH staffs have little or no EHR experience before implementation. A factor across themes is insufficient system and process knowledge, compounded by compressed implementation schedules. Increased, proactive self-education, via available outside partners and information resources, will mitigate difficulties and aid CAHs in meeting increased CDS requirements in MU Stages 2 and 3. 


\section{Correspondence to:}

Catherine K. Craven, PhD(c), MLS, MA

MU Informatics Institute

PO Box 7702

Columbia, M0 65205 USA

Email: catherine.craven@gmail.com.
Appl Clin Inform 2014; 5: 92-117

DOI: $10.4338 / \mathrm{ACl}-2013-08-\mathrm{RA}-0066$

received: August 29, 2013

accepted: December 12, 2013

published: February 12, 2014

Citation: Craven CK, Sievert MC, Hicks LL, Alexander $\mathrm{GL}$, Hearne LB, Holmes JH. CAH to CAH: EHR Implementation Advice to Critical Access Hospitals from Peer Experts and Other Key Informants. Appl Clin Inf 2014; 5: 92-117 http://dx.doi.org/

10.4338/ACI-2013-08-RA-0066 


\section{Introduction}

In 2010, the US began its national rollout of certified, integrated electronic health record systems (EHRs) through which hospitals and providers adopt and use EHRs according to reporting criteria known as Meaningful Useful (MU), mandated and funded by the $2009 \mathrm{HITECH}$ Act portion of the American Recovery and Reinvestment Act [1]. Before 2010, "Only 11.9\% of US hospitals had basic or comprehensive EHRs, and most were larger, urban academic hospitals, which can mandate use by providers. ${ }^{8}$ Although $86 \%$ of US hospitals are community hospitals, ${ }^{9}$ only $6.9 \%$ of them had even a basic clinical information system. ${ }^{10 \text { " }}$ [2] The US government wants all smaller hospitals, including the 1,328 Critical Access Hospitals (CAHs) [3], which comprise nearly a quarter of US hospitals [4], to implement integrated EHRs so that clinical quality improvements from such systems would benefit all sections of the population, including the $21 \%$ that are rural [5]. $\mathrm{CAH}$ is a special US federal designation; CAHs are certified to receive cost per service plus 1\% reimbursement from Medicare, as opposed to the prospective payment that other hospitals receive [3]. CAHs must be located in rural areas and meet the following criteria: be located greater than 35 miles from another hospital 15 miles in mountainous terrain or areas with only secondary roads; provide 24-hour emergency services, with medical staff on-site or an on-call staff available on-site within 30 minutes, 60 minutes if certain frontier area criteria are met; have a maximum of 25 acute care and swing beds; and maintain an annual average length of stay of 96 hours or less for acute care patients [3].

Rural and small hospitals have been adopting EHRs to meet MU, receive reimbursements for system costs and avoid Medicare reimbursement penalties, but "they are lagging behind larger and urban hospitals. In 2012, 66.5\% of all rural and 61.7\% of small hospitals still had no EHR" [6]. In 2011, only 113 CAHs had completed attestation reporting for MU Stage 1 [7]. According to the Office of the National Coordinator for Health Information Technology (ONC), a combined total of 591 CAHs and other small rural hospitals received MU incentive payments in 2012 [8]. The authors conducted a comparison of lists of current CAHs [9] and all hospitals as of December 31, 2012 to receive MU incentive payments [10]. The results show that $228( \pm 4)$ CAHs have received incentive payments. This does not include those CAHs that attested to MU Stage 1 by the Nov. 30, 2012, deadline but have yet to receive incentive payments.

Even if 200 more CAHs attested to MU Stage 1 in November 2012, this would indicate that approximately 900 of the 1,328 CAHs are in process or have yet to begin EHR implementation. One of two main conclusions in a Robert Wood Johnson Foundation-funded study (July 2013), Early Results from the Electronic Health Record Incentive Programs, is that "Lower rates of participation among smaller hospitals and Critical Access Hospitals merit close monitoring to ensure that broad adoption is achieved" [11]. Although CAHs are the focus here, it is of international importance that in the coming years many similarly small, rural hospitals will undertake EHR implementation to meet the World Health Organization (WHO) health information technology (HIT) adoption recommendations for member states [12].

As EHRs were adopted in larger hospitals, two consensus studies $[13,14]$ and some multi-hospital field studies on implementation processes were conducted $[15,16]$, along with many case reports $[17,18]$. Socio-technical factors, which drive and impact implementation processes, are emerging as the determinants of successful HIT adoption [19].

Many factors differ between larger hospitals and CAHs, which have smaller facility and staff sizes; limited services; fewer beds; few hospitalists; many part-time nursing staff, "prn" nurses who are scheduled only occasionally; flat management structures; and much lower total margins [20]. Advice about implementing an EHR in CAHs and similar small, rural hospitals might be different from what has been learned from larger hospitals $[13-16,21]$ or focus on specific aspects. Therefore, as part of a larger, ongoing study examining EHR implementation planning and preparation processes at CAHs, we interviewed 41 key informants to learn what aspects of implementation they have the most concerns about and gather the advice they would give to CAHs. The aim here is translational: To disseminate evidence-based findings from the informatics research realm to frontline staff at CAHs and other small, rural hospitals, who are or soon will be implementing EHRs. Of necessity, these staff must rapidly become knowledgeable about applied clinical informatics. Although this study and the larger work of which it is a part begin to identify differences between implementation processes at CAHs and larger hospitals, the primary objective of this study is to distill expert imple- 
mentation advice for CAHs with an emphasis on peer experts from CAHs, whose input is new within informatics discussions. The primary goal is to inform and benefit frontline staff at small, rural hospitals and other stakeholders who participate in and influence their implementation processes.

\section{Methods}

Other studies have included interviews with operational experts but often rely on a single category of expert, and the focus has been larger hospitals [21]. We selected 41 experts from across a wide spectrum of categories and included newly minted operational informatics peer experts - those staff at CAHs who have recently implemented EHRs. These experts represented multiple stakeholders familiar with all facets of the implementation process. The spectrum of experts included:

- Sixteen peer experts (seven Chief Executive Officers, one Chief Operating Officer, three Directors of Nursing, three IT Directors, one HIM Director, one Registered Nurse) from ten CAHs (in Kansas [one], Minnesota [three], Missouri [two], Nebraska [three], and North Dakota [one]) who have recently participated on EHR teams and implemented EHRs;

- Three vendor representatives from companies with large CAH market shares (at CPSI, Healthland, Quadramed);

- Seven implementation experts from vendors of systems for community and larger hospitals (at Allscripts, Cerner, Siemens);

- Six consultants working in the EHR market (at Deloitte Consulting, LLP; Collaborative Health Systems, LLC; Clinical Information Systems Consulting, LLC; SISU Medical Solutions, LLC; Quammen Healthcare Consultants);

- Three staff members working with CAHs at Regional Extension Centers for HIT (RECs) (in Illinois, Kansas, Tennessee);

- Two people in positions to affect national EHR policy (ONC's Deputy National Coordinator for Programs and Policy; National Quality Forum's Vice President for HIT);

- Four internationally recognized researchers in clinical informatics and health information technology policy (at Harvard Medical School, Oregon Health and Science University, University of Pennsylvania).

Our project used qualitative research methods. Each expert was interviewed individually via telephone and the conversation was recorded. Each was asked two questions:

1. What are the things you'd want to know most about the planning and preparation processes for EHR implementation at CAHs? Name two.

2. What advice would you give CAHs on the planning and preparation processes for EHR implementation?

In addition, demographic questions were asked regarding the participants' current positions, years of experience, and educational background. Peer experts were asked additional questions regarding their role in EHR implementation at their CAH, when implementation occurred, with which vendor, and whether or not the CAH had attested successfully to MU Stage 1. These questions were asked primarily to verify experience. There were no pre-determined prompts for the two main questions, but rather the interviewing author (CC) probed areas of importance to participants as they arose, and after main responses, areas not mentioned.

Phone interviews were conducted during two periods, December 2011-June 2012 and January 2013. An initial analysis was conducted on interviews from the first period, which resulted in 19 themes [22]. During the second period, ten additional people were interviewed to ensure data saturation from those directly involved in implementation at CAHs: Nine more peer experts and a consultant working with CAHs. We wanted to see if additional themes were generated, if the ordering of themes' importance by numbers of respondents commenting would change, and if additional recommendations were brought forth.

Transcripts were prepared from each interview, and methods standard for grounded theory were followed for qualitative coding analysis [23]. The first author (CC) manually conducted in vivo coding on the transcripts to extract experts' comments in their own words, and a second author 
(MS) reviewed the coding to reach agreement [24]. A second round of focused coding by these authors produced themes that emerged from the data and allowed grouping of comments by theme [24]. University of Missouri's Health Sciences Institutional Review Board approved the study.

\section{Results}

Nineteen themes were generated from expert comments:

- EHR Team;

- Communication;

- Clinician/Physician Buy-in/Ownership;

- Budget/Financial Resources;

- EHR System Selection;

- Preparatory Work;

- Technology;

- Optimization/Ongoing Work;

- Outside Partners/Information Resources;

- EHR Training/Go-live Support;

- Workflow/Productivity;

- Project Management;

- Purpose/Goals;

- Leadership;

- Change/Encouragement;

- Policy/Meaningful Use;

- Governance;

- System Install/Go-live;

- Clinical Decision Support/Knowledge Management.

Table 1 presents, by category, the number of experts who made comments that comprise each theme. No new themes arose from the second round of interviews and analysis; however, the overall ordering of the themes shifted. What is most striking is the difference between how the themes are ranked by number of all experts commenting versus a breakout of how themes are ranked by number of CAH peer experts who commented. See $>$ Table 2 for a full comparison of these theme rankings before and after the second round of data collection and analysis.

Although each theme includes interesting, useful comments, space limitations do not allow for all to be presented. Therefore, results presented below are for five selected themes: The first, second, and fourth themes as ranked by number of $\mathrm{CAH}$ peer experts who commented; the theme they ranked seventh, which is an intersection of peer experts and the other key informants on the value of outside expertise; and one theme important for ongoing MU stages on which no peers commented but other experts commented significantly. Table 3 (a-f) contains comments made for the remaining 14 themes. In this way, implementation suggestions for CAHs and small, rural hospitals from their own peers is emphasized in order of importance to those peers, followed by areas for discussion that peer experts might not realize yet will be of increasing importance. All distinct comments from all experts are included in the results to provide maximum input on these key themes. Comments comprise in-depth advice on multiple aspects of various implementation stages. All statements in the results section are direct quotes or closely paraphrased comments made by experts. A glossary of term definitions for frontline staff new to EHRs and their implementation is provided in $>$ Table 4 .

\section{Theme 1: EHR System Selection}

\section{CAH peer experts $(7 / 16)$}

- Take advantage of EHR selection assistance offered by your state's Regional Extension Centers for HIT (RECs), state hospital associations, or other groups of hospitals. 
- Create a realistic, strategic decision matrix that is hospital-specific to evaluate each vendor considered.

- Look at multiple systems; many CAHs default to the vendor that already provides their financial modules because it seems like the cheapest option, and they assume the clinical modules will integrate seamlessly with the financial modules.

- Understand the difference between interfacing, and integrating with a single system, then make the case justifying the approach to take; one Missouri CEO said,

"We decided to scrap a clinical system we'd gotten the previous year in order to integrate and avoid more interfacing."

- Don't assume that systems are box-ready. Ask vendors what must be "built" and what that means.

- Ask vendors to show how a system does what they say it will do.

- As part of the selection process, take a group of staff from various departments to visit one or more CAHs that use the system under consideration, observe how the system works, and ask about the staff's stories of system "build," installation, go-live and ongoing use.

- Verify which stages of MU each module will help meet. As a Missouri IT Director said,

"Seeing it on paper or in a webinar is one thing; seeing it in the environment gives you an idea of how it's really going to work."

- A Nebraska CEO said,

"It can be hard to pry people from their desks, but it paid off in the long run. We took 20 people on the road."

- Involve a physician in the selection process if possible.

- All involved must understand and vet how the ordering process within CPOE (computerized provider/physician order entry) will work.

- Ask if the ER system is the same as the inpatient system - will they have to re-enter any orders entered on the ER side if the patient is admitted? This issue makes physicians unhappy and can cause billing problems.

\section{Others}

Other respondents included one from the larger vendors, two consultants, and one policy expert.

- Include in the selection process all stakeholders who will use the system.

- Be aware that sales people are purposefully not trained in all functionality details because that would defeat the company's sales purpose.

- Find out how much flexibility is actually being offered regarding configurations, content, design options and user interfaces.

- Ask the vendor what reports and real-time dashboards are offered to automate data currently collected and tracked for regulatory and internal reporting; this can help you find a return on investment in addition to meeting MU.

\section{Theme 2: EHR Team}

\section{CAH peer experts $(6 / 16)$}

- It's critical to form a strong EHR team including staff from across all hospital areas (e.g. financial, IT, Director of Nursing, surgery, lab, social services, quality assurance, radiology, health information management [HIM]).

- You must have the IT Director and CEO on the team.

- Include more people upfront who know processes, not just department heads, and include those who know the backend of clinical data flow, such as HIM.

- Financial people must be on the team, even if the hospital chooses the same vendor that has provided the existing financial modules; the data flow into the financial modules will change, so the 
financial processes will be affected. As a Nebraska Director of IT noted, they experienced this, even though

"We'd had the same vendor's financial system since 1996!"

- Also, if there are project proponents, "cheerleaders," on the team from various areas, these voices can express the same messages: Some staff might hear those voices better than the CEO's.

- More than one team member needs to learn key things, such as how to access the vendor's predesigned order sets and tailor those. As a Missouri Director of Nursing said,

"If you don't have backup, and someone leaves - they're in the National Guard and have to head to Kandahar -you'll have a knowledge deficit."

- Get a commitment from a physician to participate at least in meetings about CPOE.

- The whole team must meet regularly and frequently, weekly or more, as the process progresses.

\section{Others}

Other respondents included two from CAH vendors, three from larger vendors, three consultants, two REC staff, one policy expert, and one researcher.

- Have a large, diversified team with CEO, managers, senior clinicians, and broad representation from each department including those who know work processes.

- The team must explicitly identify who from the team is the project leader and who will be the "owner" of each module, who makes sure that module gets built correctly and staff are properly trained; the IT Director is not the owner of all of these. Include backup owners for each module, too.

- Include staff who will do build work and those who will be super users.

- Consider appointing a designated partial FTE-person besides the IT or Nursing Directors, who will continue to troubleshoot and oversee EHR issues after go-live, even if that position is part time; often this is a nursing staff member other than the Director of Nursing, who is an integral team member but wishes to delegate such duties after go-live.

- From the start, meet regularly and frequently as a whole team, not sporadically, set expectations for each member, and empower him or her.

\section{Theme 4: Preparatory Work}

\section{CAH Peer Experts (5/16)}

- It's important to get details from vendors on what "build" entails for each module and report. A Nebraska Chief Nursing Officer said,

"Get more details on how much time it will take, like for the pharmacy module, at least a week, and on what information will be needed - all the medications - and ask why."

- Another Nebraska CEO gave this example:

"There's a great report for MU reporting, but it has to be built from the ground up and not onsite. We had a 2-hour webinar, and we must have gone through that five times to make it."

- A North Dakota Director of Nursing said,

"Find three hospitals that are using your vendor's system already, and visit them before you build. Talk to them about their documentation build. Really find out what it means to build and how your choices affect what the end-product looks like and works before you do it."

- Avoid duplicating electronic forms as you create them. 
- Prior to go-live, as many staff from each department as possible should make use of the test system to really test regular and atypical but possible scenarios in what's been built.

- If staff needs them, conduct basic computer skills training prior to EHR-specific training; one way for them to continue to practice is using hospital email regularly.

- A Nebraska CEO offered this caution to vendors:

"Staff at CAHs wear a lot of hats regularly and during implementation, so be mindful of overscheduling, overlapping scheduling. We had people building forms and at the same time they needed to be trained as super users."

- Be aware that the skills and knowledge levels of the vendor's build-training and go-live team members will vary significantly. Explicitly ask how experienced these vendor staff members are prior to their arrival onsite at the hospital, and insist that experienced members, rather than brand new staff, participate.

\section{Others}

Other respondents included two from CAH vendors, three from larger vendors, and one consultant.

- Pay attention to vendors, and take their advice (e.g. thoroughly clean up data files before data conversion).

- Assess staff's basic computer skills and do necessary training early. A larger vendor staff member emphasized making use of a system's training environment, if your vendor offers one:

"Training should not start right before go-live. No, no, no! What happens is chaos. Users don't buy in and metrics are skewed. This can start up to six months before go-live."

- Have a meeting space ready for when the vendor sends people onsite and for user training.

- Make sure all lab accreditations, nursing and physician licensing, and DEA numbers, state licenses, etc., are updated in advance of this process.

\section{Theme 7: Outside Partners and Information Resources}

\section{CAH Peer Experts (4/16)}

- Create and/or participate in existing user groups for the vendor and system within the state and region for ideas and to share best practices for implementation and adoption. One Nebraska CEO said,

"More partnering, less competition!"

- The EHR team should build a partnering relationship, a buddy system, with hospitals visited during selection: You can check back with them after go-live on how to change the system and work together to troubleshoot issues when the vendor doesn't know the answer.

- Ask for assistance from your REC or another regional organization for help in understanding policies such as MU.

\section{Others}

Other respondents included two consultants, one REC staff, and two researchers.

- The EHR team must go beyond what the vendor says and have a mind of their own. Don't try to do it alone.

- Find a credible source to help you navigate the waters. Reach out to colleagues and sister hospitals; if your hospital is truly freestanding, partner with others even if you're not merging or combining. One consultant said,

"Get past the okay-but-you-show-me-yours-first issue. Don't reinvent the wheel!"

- A REC staff member said,

C) Schattauer $2014 \quad$ C. K. Craven et al.: EHR Implementation Advice to Critical Access Hospitals from Peer Experts and Other Key Informants 
"Use me, your REC staff person, I am your liaison to ONC, CMS and Medicaid and this state for required in-state reporting!"

- Find and rely on validated materials on implementation: Learn from the past and look at published papers and books to see what others' experiences have been. One researcher said,

"Check out the 2003 Ash et al. national consensus paper on implementation! I've been bowled over by the number of papers now giving credit to that paper as the reason for an implementation success."

- Another said,

"The ONC website has a link to an online guide on 'Unintended Consequences of Electronic Health Records,' prepared by the Rand Corporation for the Agency for Healthcare Research and Quality. Use this: www.ucguide. org/index.html."

\section{Theme 19: Clinical Decision Support and Knowledge Management}

No peer experts commented. Two others commented.

- One national policy expert said,

"Understand what is your evidence-based knowledge-management practice - everything from structured terminology on up to evidence-based guidelines - and know where these live within the system."

- A researcher with significant national policy influence said,

"CPOE is really important and foundational, and the key is what sort of clinical decision support is put into place: Start low and go slow, then ramp up."

\section{Discussion}

The inclusion of CAH peer experts who have undertaken EHR implementation brings new voices and operational informatics experiences from small, rural hospitals to informatics discussions to an extent not possible before. That no new themes resulted from the second round of interviews to include additional CAH peer experts demonstrates that data saturation may have been reached and that the advice provided here for other CAHs - the primary study objective - is well supported. However, foci have emerged that have implications for CAHs and small, rural hospitals that have yet to implement EHRs, as well as for other stakeholders directly involved in or having potential impact on implementation processes.

Only 17 of 19 themes generated include comments by CAH peer experts ( Table 1 ), which points towards potential gaps in $\mathrm{CAH}$ peer expert knowledge. When themes are ranked by the number of all experts who commented on each versus the number of CAH peer experts who commented ( Table 2), there are differences regarding areas of most concern, based on actual difficulties that CAH peers experienced as members of their EHR implementation teams. These differences also point to a possible lack of understanding about CAHs by other experts. The top five themes from all experts are as follows:

1. EHR Team,

2. Communication,

3. Clinical/Physician Buy-in/Ownership,

4. EHR System Selection,

5. Preparatory Work. 
The top theme ranked by CAH peers only, however, is EHR System Selection. Major regrets include automatically going with their lowest bidder, often the same vendor as their existing financial system; incorrectly assuming EHRs are turnkey systems and interoperability among a vendor's modules is seamless; and not visiting other CAHs to see prospective systems in use and ask their counterparts in-depth questions. Starting such visits during selection would be highly valuable for self-education about live system functionality versus sales demonstrations, and as the foundation for cooperative knowledge building. This crucial investment would be worth travel costs and staff time.

The theme ranked first by all experts and second by CAH peers is EHR Team. CAHs recognize the importance of EHR teams, too. They are forming teams comprising six to nine members. Due to CAHs' small staff sizes (e.g. 100-150 people), teams include the CEO, CFO, and most managers, of whom there are usually a half dozen total, most of whom are also clinicians, a strength and potential advantage over larger hospitals. Major regrets include not meeting frequently enough as a whole or not including, from the start, enough non-managerial staff who know daily processes.

The theme ranked second by all commenters but third by CAH peers is Communication. Communication is important to implementation at CAHs as it is in other settings. However, unlike comments that peer experts made for other themes, their comments on communication were mainly about successful efforts rather than difficulties. As such, the comments are in $>$ Table 3 to meet space limits. CAH peers did express one regret: They should have communicated more from the EHR team outward to other staff.

The theme ranked third by all experts is Clinician/Physician Buy-in/Ownership. Notably, this theme is ranked $12^{\text {th }}$ by $\mathrm{CAH}$ peers, which indicates that other experts may not understand factors at CAHs: Few CAHs employ hospitalists, so physicians are often not at the CAH, do not play major roles in operations, and are not EHR team members. Their buy-in is necessary but usually accomplished through the Board and CEO explicitly setting priorities with medical staff and via CPOE training and, more rarely, build. Nurses and ancillary staff are the primary clinical leaders in operations and implementation. The Nursing Director plays as critical a role on the EHR team as the IT Director.

The fifth ranked theme for all experts, Preparatory Work, was ranked fourth by CAH peers. A major peer expert regret is not knowing enough going into the build process. They advise others to ask specifics of vendors, e.g. work hours required for each module at the last several CAHs, and have build teams visit other CAHs using the same EHR to see the system in action, ask questions, and hear their build stories. CAHs are implementing in compressed, MU- and vendor-driven timelines much more quickly than larger hospitals have in the past, sometimes in as little as six months rather than over multiple years; the "test" phase of building is often just a few days, if it happens at all, before go-live [20], so understanding as much as possible beforehand is especially important for preventing stressful realizations and frustration at go-live, and the need to redo forms/orders-sets.

The next theme included in the results, Outside Partners/Information Resources, is an area of agreement between peer and other experts and encapsulates a major factor underlying the CAH peer regrets expressed across their top ranked themes: CAHs are going in blind and don't understand as much as they should before or during implementation. In hindsight, peer experts realized they should have made more use of outside resources - and that there are resources other than consulting firms, which CAHs often cannot afford. Many CAH managers and staff have never worked anywhere with an EHR. CAH IT staff is often new to healthcare. Having little or no prior experience using EHRs and no validated information about implementation beyond vendor instructions is the team norm at CAH kickoff meetings, unlike at larger hospitals. The team then is so consumed by preparation work in a highly compressed timeframe that they are unlikely to look for other resources even if the thought occurs, much less across multiple websites (e.g. AHRQ, CMS, HRSA, RECs, ONC).

Peer experts emphasize the importance of partnering more with other CAHs and seeking more REC assistance. However, RECs vary in how much help they offer, not all provide links on their websites to authoritative resources, and EHR team member knowledge about what they offer varies. ONC has recognized the need for more educational resources and has ramped up links on its website to include many implementation resources. However, none of the peer experts mentioned using or seemed aware of these ONC resources. When asked explicitly, no one at the four CAHs in the larger onsite study knew of the existence of ONC website resources [20]. When shown a printout of 
Meaningful Use and Critical Access Hospitals: A Primer on HIT Adoption in the Rural Health Care Setting published online in December 2010 [25] only one person, an IT Director, "thought" he had seen it somewhere [20]. No one was aware of the peer-reviewed literature on implementation and adoption [20].

To foster success, policy makers should consider supplying an online repository of validated resources, including citations and PDFs for peer-reviewed studies, and tying meaningful use of these implementation-related educational resources into an HIT adoption program's registration and reporting stages. In this manner, they can ensure that stakeholders are more uniformly aware of and learning from such resources upfront and in stages as their EHR knowledge grows and information needs evolve. Other countries forming national eHealth strategies to meet WHO goals should consider this, especially if decisions are centralized, and as a result, few or no small, rural hospital staff members will take part in the vendor/system selection process, and when the timeline for implementation is compressed.

Clinical decision support (CDS)/knowledge management (KM), the final theme included in the results, is one for which no CAH peer experts made comments but nationally recognized experts influencing MU policy did. In the second round of interviews, the authors purposefully probed CAH peer knowledge of these areas. Some had heard of CDS. None knew what these are. See $>$ Table 4 for definitions. For MU Stage 1, CAHs only need to incorporate one CDS rule, which their vendors take care of with little explicit discussion [20]. CAHs must incorporate increased CDS to meet MU Stages 2 and 3 requirements. CDS/KM relate strongly to ongoing EHR optimization and build-out, about which CAH peers have little knowledge. Their usual assumption is that once initial post-go-live troubleshooting is completed, the system is done. In reality, the work of EHR owners is perpetual. Their lack of knowledge about optimization and build-out, particularly via increased CDS, is a major gap. A study limitation is the lack of second-round interviews with $\mathrm{CAH}$-market vendors and REC staff working with CAHs to probe their points of view about this gap. ONC did contract with experts to create a free CDS toolkit for providers and CAHs, available online as of October 2013. - Table 5 includes citations for this and other resources that CAHs will find useful for proactive education on implementation- and EHR-related topics.

\section{Conclusion}

EHR implementations will always be complex projects. They do not have to be painful odysseys into the complete unknown. Through connecting more closely with peers to share lessons learned and EHR knowledge, and by seeking the existing collective implementation expertise, CAHs and small hospitals can avoid recreating the wheel and ensure their own successful EHR implementations and adoption. Now that the pool of $\mathrm{CAH}$ peer experts has increased and their experience continues to deepen, vendors and other stakeholders should learn from the experiences of these newly minted experts. From what CAH peer experts and others explicitly stated and what can be inferred here, all stakeholders can improve their own processes and tailor approaches specifically for small, rural hospitals and other CAHs.

\section{Clinical Relevance Statement}

Critical Access Hospitals (CAHs) can improve their electronic health record system (EHR) implementation processes by following specific points of advice presented here from multiple types of implementation experts. Recommendations especially from peer experts, $\mathrm{CAH}$ staff who serve on EHR teams and have recently implemented EHRs, will guide other CAHs and similar small, rural hospitals through areas in which they learned key lessons. From what CAH peer experts and others explicitly state, and what can be inferred, stakeholders who have vested interests in small, rural hospital EHR implementation and adoption success to meet health care goals can improve their own processes and tailor approaches specifically for these small hospitals.

\section{Conflicts of Interest}

The authors declare that they have no conflicts of interest in this research. 


\section{Protection of Human and Animal Subjects}

The study did not involve humans (exempt status) or animals, and the study was reviewed and approved by the University of Missouri Health Sciences Institutional Review Board.

\section{Acknowledgements}

This study was funded in part by US NIH NLM Grant \# 5T15LM007087-17. The authors wish to thank the following organizations and individuals without whom this study would not be possible: the study participants; additional staff at the Regional Extension Centers for HIT in Arkansas, Illinois, Kansas, Minnesota and North Dakota, Missouri, Nebraska, and Tennessee; Russell B. Leftwich, MD, Chief Medical Informatics Officer, State of Tennessee Office of eHealth Initiatives; Paul Kleeberg, MD, Chief Medical Informatics Officers, Stratus Health and Clinical Director, Regional Extension Assistance Center for HIT (REACH) for Minnesota and North Dakota; and EHR team members and staff at four CAHs in Arkansas, Kansas, and Tennessee, who are participants of the larger field study of which this work is a part. 

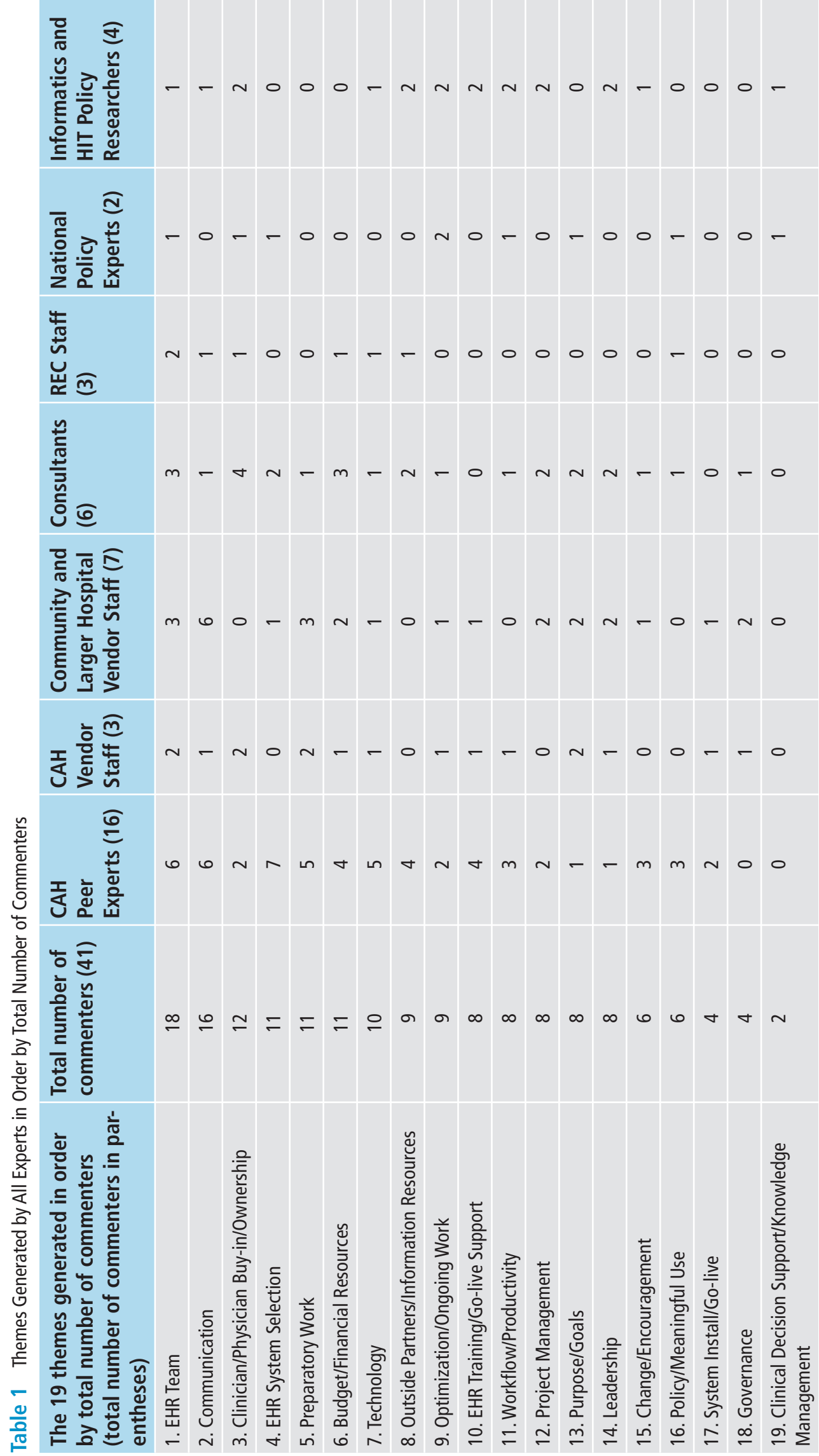


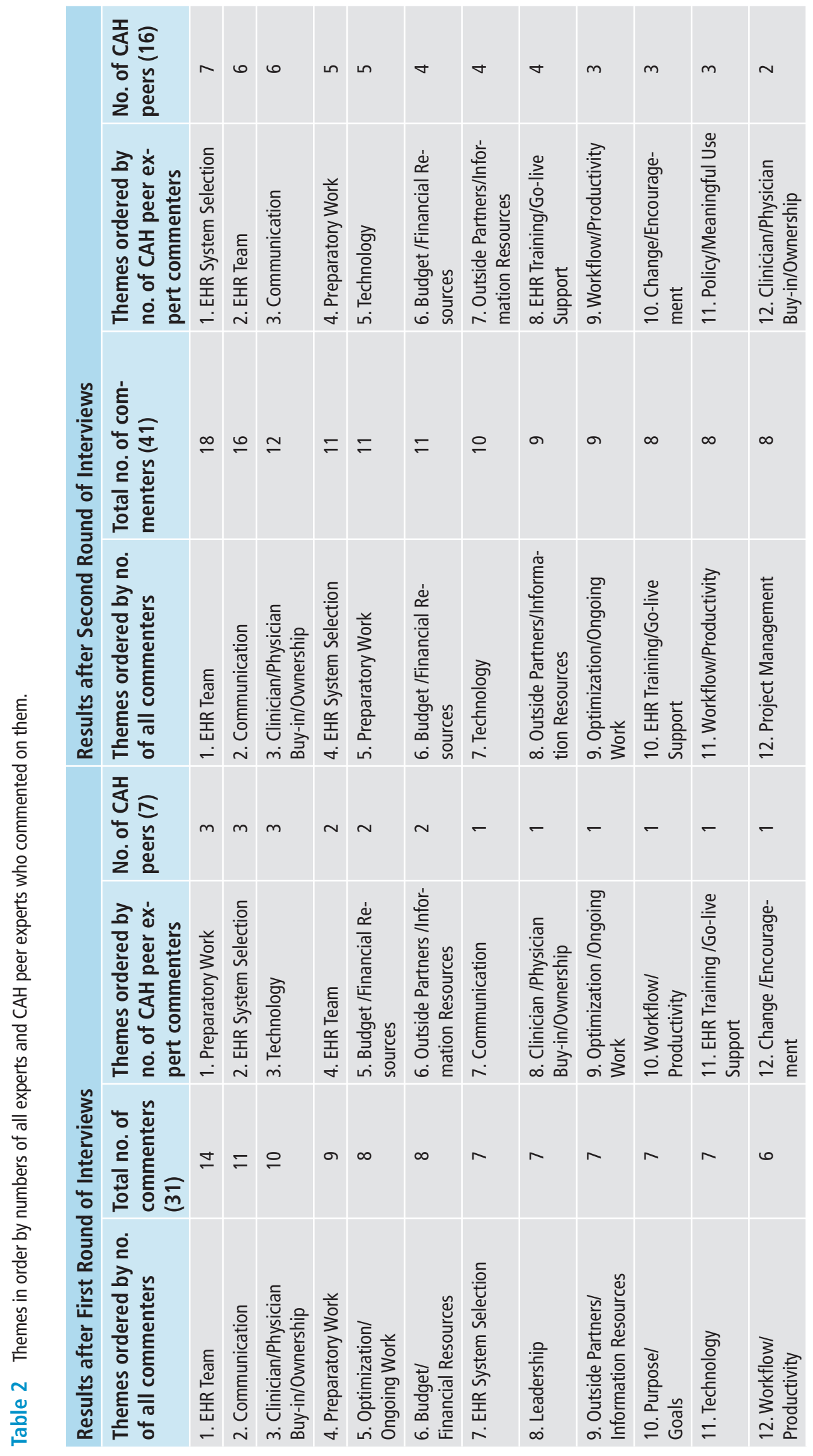



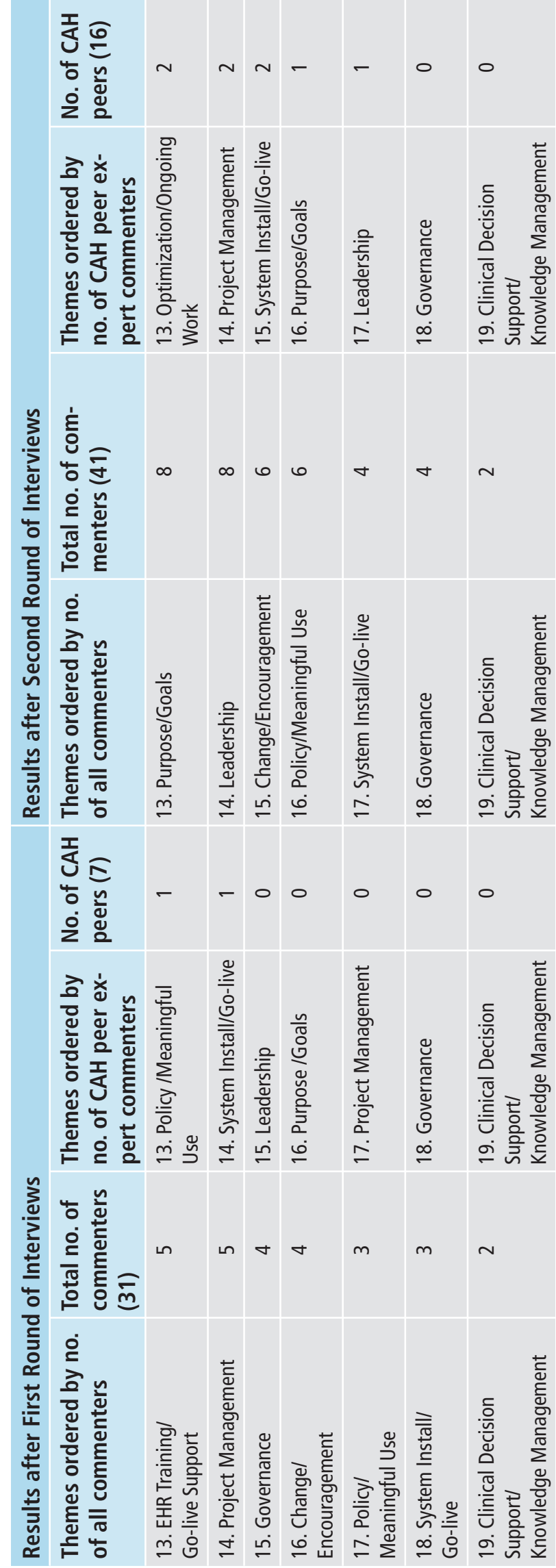
Table $3 a$ Comments for the 14 remaining themes: expert advice to CAHs and small, rural hospitals. Themes in Table 3 (a-f) are in descending order according to the number of CAH peer experts who commented on each. The top box under each theme contains the peer comments. Other experts sometimes made similar comments; however, only unique comments made solely by others are included in the bottom box under each theme.

\section{Communication}

- Communicate out from the EHR team to all staff much more than you think necessary.

- Be transparent and thorough; you'll undercut yourself doling information by the spoonful.

- When the team has an important message to get out, have an event, such as a meal, and spend 10 minutes on the message.

- Throughout the process, the team should plan and promote a series of fun and informative happenings, especially during build and go-live.

- The EHR team should hold a project kickoff meeting with vendor staff and do something special that staff will enjoy based on their preferences (e.g. a potluck versus catered meal).

- At the beginning of the project create a mission statement and graphics for the project (e.g. C.A.R.E. for Clinical Excellence, Accelerated Growth, Regional Leadership and Employee Satisfaction). Put it on everything (e.g. the website, banners, t-shirts) to create consistency and continuity in messaging, and staff buy-in.

- It's imperative to communicate with physicians throughout the process. EHR updates/issues should be a standing agenda item for medical staff and all other departmental meetings.

- Put out a newsletter every Friday, with details on what happened during the week, what's on the horizon, what successes and failures occurred, and how the team will retackle whatever didn't go as smoothly as hoped.

- Have a countdown clock on a computer screen in the cafeteria that shows days, hours, and minutes until golive, and take photos of staff in front of it as it hits zero, zero, zero.

- The day before go-live give out pens that say "the last pen you'll ever need."

- Promote and have a celebration at go-live to relieve stress (e.g. set up a fake margarita bar and have the CEO and EHR team hand out snacks; provide green-for-go-live t-shirts with the mission statement to vendor staff and super-users to wear at go-live.)

- (N.B. Vendors emphasize electronic means. Peers suggest these but verified that they also employ the low-tech standbys they use for regular departmental/staff updates, e.g. binders and bulletin/white boards: Ingrained sources for updates that staff check regularly already are often more effective, especially to reach the many nurses who work only periodic shifts and don't check the CAH email.)

- Remind everyone constantly why you're doing this and that it's not about technology.

- Create a communication plan rather than expecting information to disseminate in an ad hoc fashion; work with the vendor, who will have samples.

- Accustom staff to using email ahead of install and go-live and checking it regularly at 8 a.m., noon, and 5 p.m.

- Do regular email blasts, newsletters, blogs, monthly "lunch and learns," even a website with a progress-toward-go-live thermometer.

- Start 30 days before go-live and send out an email to all-staff every day, just alerts without much detail; content might include how many days until go-live, how the rollout will work, who will be involved, which departments will be affected when, how many extra hours will be needed, what will happen until paper records are gone.

- Continue sending out regular bulletins after go-live about what's being learned and how to do things in the EHR. 
Table 3b Comments for the 14 remaining themes: expert advice to CAHs and small, rural hospitals.

\section{Technology}

- With your vendor conduct a thorough inventory of existing versus needed for hardware, peripherals, network components, vendor modules necessary to meet $\mathrm{MU}$, and software interfaces or third-party software to bridge the EHR and existing systems (e.g. PACs) or fill in gaps in the vendor's system for needed functionality (e.g. third-party billing clearinghouse).

- Go with as few interfaces as is necessary.

- After EHR team narrows choices for tablets, laptops, barcode scanners, computer carts, have a device fair at the hospital where vendors present. Invite all staff including physicians and take a vote on wants; consider purchasing a mix of devices to satisfy different users.

- Examine closely where staff will need more network drops; get the wireless network going/upgraded well before go-live.

- Double-check vendor specifications before making purchases, esp. on printers.

- Learn whether and how the EHR will exchange information with your local clinics and state health department.

- Don't make assumptions about interoperability (e.g. between existing systems and the EHR, a vendor's financial and clinical modules, current and next EHR version).

- Don't underinvest in peripherals, devices, or network routers; be frugal but don't skimp or performance will suffer.

- Examine how you are managing system/network security, especially patient access.

\section{Budget/Financial Resources}

- Create a detailed and realistic budget for resources allocation, including human resources, to do this rapidly, and determine whether and how you'll get those.

- You'll need a permanent, full-time IT staff member. Most hire rather than contract.

- Given the significantly greater resource constraints CAHs face over larger hospitals, they must think about the strategies and tactics they'll use to tackle the challenge, scope, time, and costs of the project.

- Include in the budget any additional help you'll need from outside contractors (e.g. for selection, data cleaning, basic computer skills, module build, training/go-live support).

- Consider what you can afford to budget for ongoing IT costs (e.g. vendor maintenance/annual fees, costs for and timing of a upgrade, voluntary or mandatory, to the next version of the system, hardware updates). 
Table 3c Comments for the 14 remaining themes: expert advice to CAHs and small, rural hospitals.

\section{EHR Training/Go-live Support}

- Create a comprehensive training plan with your vendor and know specifics (e.g. How much webinar versus onsite end-user training? When? To what extent is it a train-the-trainer model - i.e. What and how much training of users do they expect your staff to do? Who trains physicians? Sometimes nurses don't want to be the first or sole trainers for them.)

- Ask how many vendor staff will be onsite for user training, at staff "elbows" for go-live, and for how long, e.g., Two staff might not be enough for a multiple-module go-live.

- Consider hiring more training/onsite go-live support than the vendor's basic service.

- Provide lots of access for staff to the test system, including icons on every PC and in dedicated spaces so users can train and test and practice simultaneously.

- Create competency checklists; have super users sit down with each user prior to go-live to check skills and remedy any areas if there are standout user-knowledge gaps.

- Make super-users available across all shifts from go-live through at least 60 days.

- Having the CEO and senior administration onsite 24/7 during go-live is beneficial for moral and practical support; they can direct vendor staff and super-users wherever assistance is needed, coordinate EHR team meetings, and provide all-staff updates.

- For new staff spend a couple of days strictly training on the EHR, followed by time on the floor, then a return to the computer so that processes and fine details make sense.

- Get lots of training.

- Don't cut corners on bringing physicians in and training them.

- Many hospitals have used the strategy of training nurse super-users on what the doctors will use, and then they become the best way to train the doctors.

- Train nurse super-users, mid-levels, and nurses from physicians' offices on CPOE.

- You'll need an ongoing training and education plan after go-live; hospitals fall down on this, so know the level you'll need.

- Know what level of ongoing training and support you'll have.

\section{Workflow/Productivity}

- Closely examine how your nurses document, and then put in time upfront to make sure the documentation module works well (e.g. navigation is smooth and the workflow is efficient for your patient types).

- Delve into how much your financial processes change now that your clinical processes are computerized.

- Set expectations about EHR use; user speed increases, but some find that their EHR processes require more time than desired (e.g. medication reconciliation) even after some optimization.

- Think about a workflow redesign process.

- Make decisions about work processes and knowledge management first; designing the software modules comes last.

- Define cases for each of your typical patient types and make sure staff, including physicians, walk these all the way through the system during go-live to ensure that all patient care steps are incorporated into the workflow and the basic data necessary for care is displaying; know how a patient gets from $A$ to $B$ and so on through the system.

- You'll revamp after go-live, but you don't want to have to back up too much afterwards.

- Workflow will change; studying it beforehand is the start to what you'll need to know. 
Table 3d Comments for the 14 remaining themes: expert advice to CAHs and small, rural hospitals.

\section{Change/Encouragement}

- Don't think this will be easy no matter what system you choose.

- It can be scary and a little overwhelming to change how things have always been done, but your team can make it happen.

- Don't discount the physicians despite concerns you might have about resistance; many, even those close to retirement have been great.

- Charting is better, and the system prompts help.

- Be very open to change; it's hard but it's worth it.

- It's like labor: a wonderful baby at the end, but it will hurt a little.

- This kind of integration is hard, it's huge, but if you can get through it, you'll be so far ahead: The impact on the community will be huge.

- Many community hospitals (just a little bigger than CAHs) have succeeded; you will, too.

\section{Policy/Meaningful Use}

- Get serious about MU compliance; know who on your staff will interpret all the rules and make sure the software will do it.

- Abide the spirit not just the letter of MU; know what a CMS audit would entail: At some CAHs they're falling short on physicians using CPOE, and others are doing it for them.

- Don't forget bureaucratic details. If your hospital is supposed to be reporting on something already (e.g. PECOS) but isn't, it could cause problems in MU attesting and reimbursement.

- Investigate early in the process regarding what your state is capable of doing regarding public health data reporting and exchange.

- Understand the deadlines, dates and timelines for MU reporting; it's a work stream.

- Learn what the reporting measures for MU are and why; some at CAHs understand these, but many staff do not understand that $\mathrm{MU}$ is designed to increase quality and decrease costs.

- Understand that even if you're already reporting on some of the clinical quality measures prior to implementation (e.g. manually extracting from paper) you must collect it electronically to be compliant with MU.

\section{Clinician/Physician Buy-in /Ownership}

- Getting physician buy-in can be a challenge, but as a CEO you must get it, and earlier is better than later. Otherwise, staff will wind up doing the physicians' work for too long, and it puts a strain on the administratormedical staff relationship.

- Involve a physician in building and optimizing the CPOE module, which is not only pragmatic, but it encourages the physician to become a champion.

- Strong-arm physicians or coach them, but the administrator cannot back down.

- Show physicians how the EHR will do something good for them (e.g. a quick way to look at allergies, vitals, home medications) before asking them to do something.

- Have a plan to understand the fears of and engage physicians: The CEO's approach can be as simple as '"We have to do this, so let's figure it out together. It will get better!"

- If there is an hospitalist at the CAH, ask her or him to be involved in the implementation since she or he is there all the time and will use the system all the time.

- Ensure that there is ownership of the EHR by all clinicians across the clinical infrastructure: They need to be the expert drivers because it's their tool to manage and grow to best manage the way they want to practice. 
Table 3e Comments for the 14 remaining themes: expert advice to CAHs and small, rural hospitals.

\section{Optimization/Ongoing Work}

- The EHR team must continue to meet after go-live and when MU is met.

- Know that optimization and ongoing work slows but never completely ends.

- Designate a partial FTE position to focus on addressing system issues, other than Director of Nursing; this is especially important if there is not an onsite IT person.

- Separate out go-live from optimization, which will continue, and put this into your long-range plan; it will take years to build out the system to where you want it to be.

- The back and forth between people and devices, constant upgrades, patches, changing standards for data/ formats/usability, changes in formulary and order sets, as well as tweaks by your IT person, mean that your system will constantly change. It's fluid.

- Vendors: Be more explicit and transparent about the fact that optimization is ongoing.

- Make sure you're actually capturing the data necessary; see what you're entering and figure out what other data elements you need to add.

- Pay attention to evaluation of the clinical efficacy of the system and its impact on the organization; look back at your key performance measures, your clinical indicators to figure out what outcomes are linked to the EHR; put these on a report card.

\section{Project Management}

- Build a real case for your strategy and make sure your hospital can handle all the change and disruption, especially if you're implementing everything all at once.

- Culture "eats strategy everyday for lunch," so managing culture change will be a major part of managing this project.

- The project leader must stay on top of timelines and hold the vendor to them; the CEO must be direct and even tough to do/assist with this.

- Designate a project leader, whether it's the CEO or other team member.

- Do a gap analysis to understand where you are before starting and what your detailed plan is to move forward.

- Develop a project timeline, assess it periodically, stick to it.

- Move quickly through implementation and pursue a "big bang" rollout rather than a progressive rollout; however, don't rush too much.

- Rely on starter order sets from the vendor if possible.

- Keep track of who is coming to meetings; be flexible in scheduling: If you have to have early or evening meetings for everyone to participate, do so.

- Have really good project management, including having your team at elbows on the floor for the first few weeks, then track problems and deal with them one at a time.

\section{System Install/Go-live}

- The EHR team and department heads should meet daily during install and go-live, both a.m. and p.m. during go-live week, tapering off to once per day, then once per week.

- As part of go-live, take all of your paper forms and find where they are in the system.

- Make it clear early to all staff (and physicians) that vacations cannot be scheduled during key install days and go-live.

- Administration should do nice things for the staff during install and go-live( e.g. cookies, cupcakes, popcorn) to say thank you.

- Create a central, living document for concerns and problems - what, when, that it's been tested again to verify the problem - so that all important issues get rolled into it, and you're not reinventing the wheel or making duplicate reports to the vendor. 
Table $3 f$ Comments for the 14 remaining themes: expert advice to CAHs and small, rural hospitals.

\section{Purpose/Goals}

- Know your own culture, and although this means work, make sure everyone on staff knows why you are doing this, and agrees that it's for a good reason, not just because it's a regulation because change for a good reason, a purpose, works much better than change for change's sake.

- If you set out the goal, for example, of going paperless, from the Board on down, you've got to set your expectations and be explicit that they apply to everyone; it's got to be non-negotiable.

- Know what your value proposition is in implementing an EHR.

- Don't think of this as an IT project; it's an operations automation project, and from the strategic level to the clinic level, it's about patient-centered outcomes.

- Articulate why you are doing this project, what you want to get out of it, and what your measurable goals are: Meeting MU? Increasing quality? Changing workflow?

- Know whether you're doing a clinical transformation project or an implementation project; if it's the later, you'll mainly fit your processes to the software, not vice versa.

- Know what "done" looks for your project charter.

- Know what your expectations for the project are: Answer to all your prayers or a task to move you along the continuum toward improved patient care? Because it's the vendor's job to sell you the product, and the hospital doesn't always have people who can critically evaluate tools, so some have unrealistic expectations; It's too easy then to make it "Oz the Great and Terrible" and want to jettison the system.

\section{Leadership}

- Make sure the Board and administration are public about their commitment to this project. That helps the other team members commit and participate.

- Make certain you've got top-down leadership and sponsorship; what the CEO and CFO know about the process is important.

- The CEO must be engaged, particularly for CAHs.

- You need departmental level buy-in from all department heads, including from Health Information and materials management departments, not just top administration.

- Clinical and operational leadership must engage fully in this process. If not, it's a recipe for disaster.

- Although most CAHs have never undergone any major undertaking like this, the ones with strong leadership and lots of communication succeed, whereas the more fragmented ones have a harder time.

- This project is an organizational change project, and it will rise and fall on how all, not just the CEO, understand, set, and guide expectations.

- Vendors must enter the environment in a respectful way and be "absorbed" by existing leadership: The voice of the project is the leaders of the organization.

\section{Governance}

No CAH peer experts made comments for this theme.

- Governance structure is necessary to roll decisions downward and advocate for this change.

- This is a fundamental piece that drives decisions: Implementations that have not been successful are ones where key decisions were made loosely.

- A good team will do all the preliminary work, but one person must make final decisions.

- Know who is going to own this solution when the vendor gone; there needs to be a physician to drive the physician system, a clinical person to drive the clinical portion. 
Table 4 Glossary of Implementation and EHR-related terms

\begin{tabular}{|c|c|}
\hline Build & $\begin{array}{l}\text { A broad term covering work that the CAH staff must do for the vendor so that the } \\
\text { EHR system can be finalized for installation and use. Some of the build process in- } \\
\text { volves providing CAH-specific data in a vendor-requested format (e.g. putting the } \\
\text { charge master and pharmacy formulary into spreadsheets). Other activities include } \\
\text { creating electronic templates for nursing documentation or physician order entry } \\
\text { within the EHR. These templates capture the work steps represented on the paper } \\
\text { forms that the CAH staff currently uses. Which forms the CAH builds and how these } \\
\text { connect will affect the look and navigation of the final EHR for role-specific tasks and } \\
\text { the overall workflow as each type of patient moves through the system. }\end{array}$ \\
\hline $\begin{array}{l}\text { Clinical Decision } \\
\text { Support } \\
\text { (CDS) }\end{array}$ & $\begin{array}{l}\text { Is "HIT functionality that builds upon the foundation of an EHR to provide persons in- } \\
\text { volved in care processes with general and person-specific information, intelligently fil- } \\
\text { tered and organized, at appropriate times, to enhance health and health care." [26] } \\
\text { CDS, which is most often integrated into the CPOE module, can include the following: } \\
\text { links to evidence-based reference sources; order templates updated with the latest } \\
\text { best-practice treatments; alerts for drug-drug interactions, patient allergies and other } \\
\text { reminders; relevant data presentation; and situation-specific flow sheets, and dash- } \\
\text { boards. [27] }\end{array}$ \\
\hline Go-Live & Date when the new system is turned on and CAH staff begins to use it. \\
\hline Integrated System & $\begin{array}{l}\text { Is one in which the component modules effectively interact with each other to ex- } \\
\text { change data smoothly, without need for purchasing additional third-party interfaces } \\
\text { to allow the components to interact. }\end{array}$ \\
\hline Interface & $\begin{array}{l}\text { Software that allows two systems to "talk" to each other so that data can move be- } \\
\text { tween them. An interface is necessary between each of a vendor's system modules, } \\
\text { but these are usually built in. Additional interfaces are necessary between the ven- } \\
\text { dor's EHR system and any systems you already have (e.g. picture archiving and com- } \\
\text { munication "PACS" or financial systems from other vendors). }\end{array}$ \\
\hline Interoperability & $\begin{array}{l}\text { The ability of two or more systems or subcomponents to work together to exchange } \\
\text { data correctly and smoothly. }\end{array}$ \\
\hline $\begin{array}{l}\text { Knowledge Man- } \\
\text { agement } \\
\text { (KM) }\end{array}$ & $\begin{array}{l}\text { Is "the process of capturing, distributing, and effectively using knowledge," [28] KM } \\
\text { encompasses CDS components, and the KM questions for the vendor become how } \\
\text { much responsibility for, access to, and control over these does the CAH team have, } \\
\text { who will update these, how, and when? [29] }\end{array}$ \\
\hline Modules & $\begin{array}{l}\text { Component parts of a system, such as the "nursing documentation" or "physician } \\
\text { order entry" or "pharmacy" clinical applications within an integrated EHR system. } \\
\text { Vendors also refer to subcomponents of a financial system, such as "accounts pay- } \\
\text { able" or "third-party billing clearinghouse," as modules. }\end{array}$ \\
\hline Network Drop & $\begin{array}{l}\text { Places where there is a physical connection for a computer to connect with the net- } \\
\text { work. The CAH will need to determine where additional drops might need to be in- } \\
\text { stalled for computer workstations to access the EHR, and when and where staff will } \\
\text { use wireless devices and a wireless network to do so. }\end{array}$ \\
\hline $\begin{array}{l}\text { Real-Time Dash- } \\
\text { board }\end{array}$ & $\begin{array}{l}\text { A type of automated reporting feature built into a user interface within a system that } \\
\text { pulls in data from various modules in real time, so that the information displayed is } \\
\text { up to date. Real-time dashboards can feature clinical or financial and other operations } \\
\text { data. }\end{array}$ \\
\hline Super Users & $\begin{array}{l}\text { CAH staff members trained by the vendor on the EHR system, or a specific module, in } \\
\text { advance of others and usually in more depth. Super users then help train other staff } \\
\text { members and serve as go-to resources when others have questions. }\end{array}$ \\
\hline
\end{tabular}




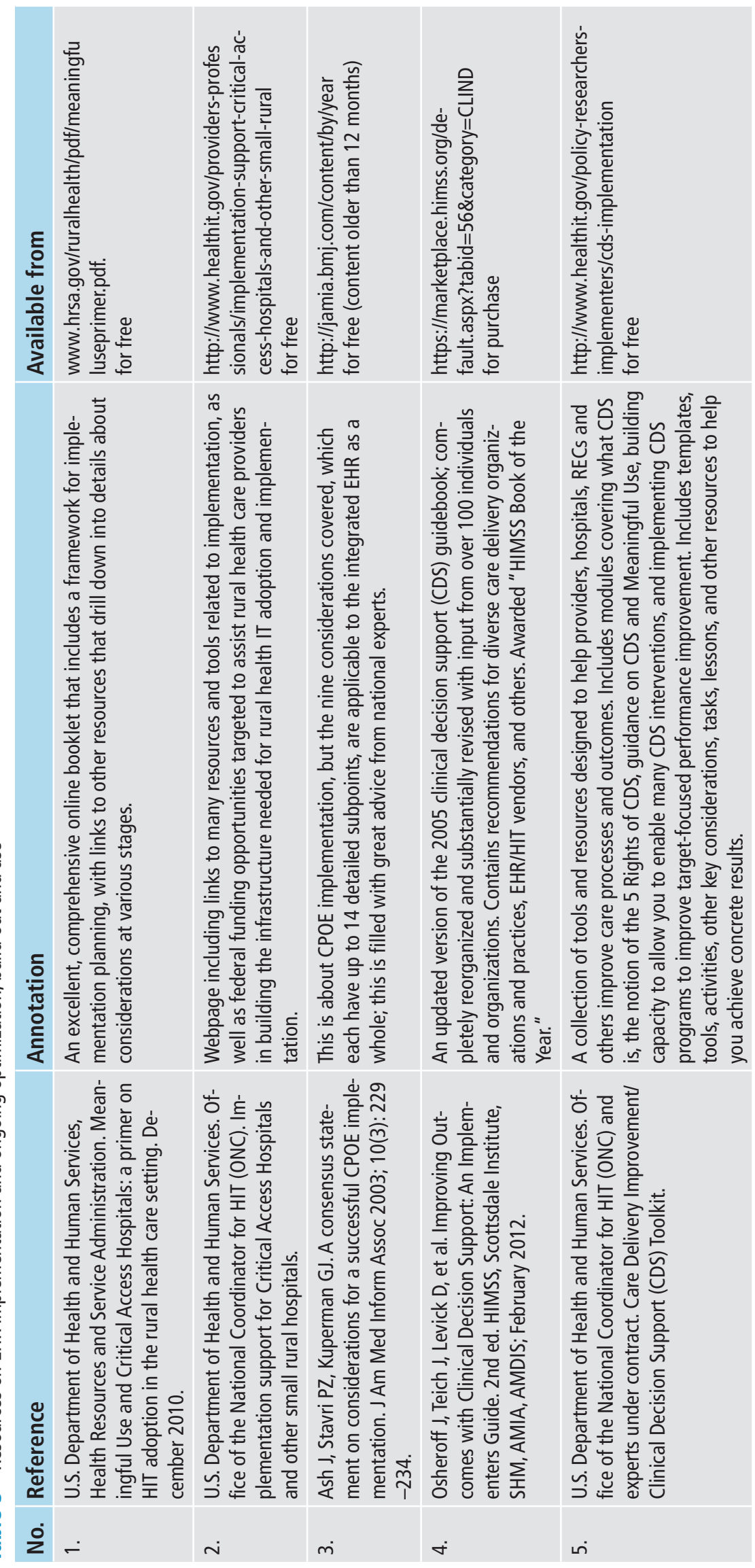




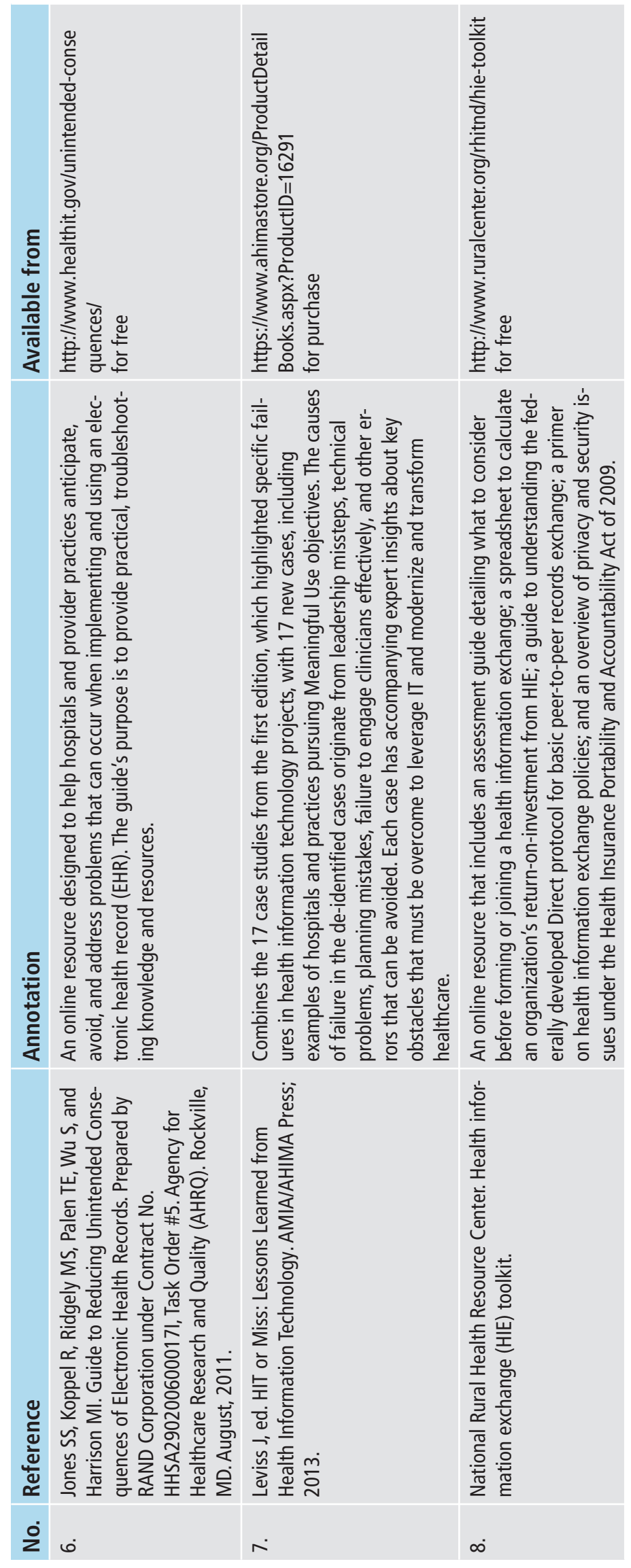




\section{References}

1. US Congress. American Recovery and Reinvestment Act of 2009. 2009 [cited 2012 August 8]; Available from: http://www.gpo.gov/fdsys/pkg/BILLS-111hr1enr/pdf/BILLS-111hrlenr.pdf.

2. Ash JS, McCormack JL, Sittig DF, Wright A, McMullen C, Bates DW. Standard practices for computerized clinical decision support in community hospitals: a national survey. J Am Med Inform Assoc 2012; 19(6): 980-987. Epub 2012/06/19.

3. Flex Monitoring Team [Internet]. About Flex Monitoring Team and Critical Access Hospitals. [updated 2010 May 26; cited 2013 July 16]; Available from: http://www.flexmonitoring.org/aboutcahflex.shtml.

4. American Hospital Association. Fast Facts on US Hospitals From 2011 Annual Survey, AHA Hospital Statistics, 2013 edition. [updated 2013 Jan 3; cited 2013 March]; Available from: http://www.aha.org/research/ rc/stat-studies/fast-facts.shtml

5. US Census Bureau. Urban/Rural and Metropolitan/Nonmetropolitan Population: 2000 - United States Urban/Rural and Inside/Outside Metropolitan Areas. Census 2000 Summary File (SF 1) [cited 2012 March 13]; Available from: http://factfinder2.census.gov/faces/tableservices/jsf/pages/productview.xhtml?pid=DEC_00_SF1_GCTP1.US93\&prodType=table

6. Desroches CM, Charles D, Furukawa MF, Joshi MS, Kralovec P, Mostashari F, Worzala C, Jha AK. Adoption of electronic health records grows rapidly, but fewer than half Of US hospitals had at least a basic system. Health Aff (Millwood). 2013; 32(8): 1478-1485. doi: 10.1377/hlthaff.2013.0308. Epub 2013 Jul 9.

7. Wenzlow L. Meaningful Use attestations in 2011: CMS/ONC raw dataset tells hospital story. In: Wisconsin Office of Rural Health online blog, Rural Health IT: What "Meaningful Use" Means to Rural. 2012 January 11 - [cited 2013 March]. Available from: http://www.worh.org/hit/2012/01/meaningful-use-attestationsin-2011-cmsonc-raw-dataset-tells-hospital-story/.

8. Leily S. Resources for Critical Access Hospitals and small rural hospitals [Internet]. Office of the National Coordinator for Health Information Technology. Weekly Digest Bulletin 2013 March 18.

9. Flex Monitoring Team. Universities of Minnesota, North Carolina-Chapel Hill, and Southern Maine: Flex Program; [updated 30 June 2013; cited March 2013]. Complete list of Critical Access Hospitals (1,331 CAH hospitals, current as of December 31, 2012). Available from: http://www.flexmonitoring.org/cahlis tRA.cgi.

10. Centers for Medicare \& Medicaid Services. Baltimore: CMS; [updated 6 November 2013; cited March 2013]. EH recipients of Medicare EHR incentive program payments 2012. ProvidersPaidByEHRProgram_Dec2012_FINAL_HOSPiTAL.csv. Available from: http://www.cms.gov/Regulations-and- Guidance/Legislation/EHRIncentivePrograms/ DataAndReports.html.

11.Adler-Milstein J, Furukawa, MF, King, J, Jha, AK. Early results from the hospital electronic health record incentive programs. Am J Manag Care 2013; 19(7): e273-e284. Epub July 10, 2013.

12. World Health Organization. Geneva: WHO; c 2013 - [cited 20 April 2013]. Directory of eHealth Policies. Keeping Promises, Measuring Results 2011. Available from: http://www.who.int/goe/policies/en/index. html

13. Ash JS, Stavri PZ, Kuperman GJ. A consensus statement on considerations for a successful CPOE implementation. J Am Med Inform Assoc 2003; 10(3): 229-234. Epub 2003/03/11.

14.Brender J, Ammenwerth E, Nykanen P, Talmon J. Factors influencing success and failure of health informatics systems - a pilot Delphi study. Methods Inf Med 2006; 45(1): 125-136. Epub 2006/02/17.

15. Aarts J. Understanding implementation: a socio technical appraisal on the introduction of computerized physician order entry systems in Dutch and American hospitals. Rotterdam (Netherlands): Erasmus University; 2005.

16. Ash JS, Stavri PZ, Dykstra R, Fournier L. Implementing computerized physician order entry: the importance of special people. Int J Med Inform 2003; 69(2-3): 235-250. Epub 2003/06/18.

17.Leviss J, editor. H.I.T. or miss: lessons learned from health information technology implementations. Chicago: AHIMA Press; 2010.

18. Miller J, editor. Implementing the electronic health record: case studies and strategies for success. Chicago: HIMSS Press; 2005.

19. Kaplan B, Harris-Salamone KD. Health IT success and failure: recommendations from literature and an AMIA workshop. J Am Med Inform Assoc 2009; 16(3): 291-299. Epub 2009/03/06.

20. Craven CK. Implementation planning processes in Critical Access Hospitals. Columbia, Mo. (USA): University of Missouri; Forthcoming 2014.

21.Poon EG, Blumenthal D, Jaggi T, Honour MM, Bates DW, Kaushal R. Overcoming barriers to adopting and implementing computerized physician order entry systems in U.S. hospitals. Health Aff (Millwood) 2004; 23(4): 184-190. Epub 2004/08/21. 
22. Craven CK, Sievert MC, Hicks LL, Alexander GL, Hearne LB, Holmes JH. Experts speak: advice from key informants to small, rural hospitals on implementing the electronic health record system. In: Lehmann CU, Ammenwerth E, Nøhr C, editors. Conducting medical informatics by converging technologies, conveying sciences and connecting people. MEDINFO 2013; Proceedings of the 14th World Congress on Medical and Health Informatics. Series: Studies in Health Technology and Informatics, Vol. 192; 2013 Aug 19-25; Copenhagen, Denmark. Amersterdam: IOS Press; 2013. p. 608-612

23. Ash JS, Smith AC, Stavri PZ. Performing subjectivist studies in the qualitative traditions responsive to users. In: Friedman CP, Wyatt JC, editors. Evaluation methods in biomedical informatics. 2nd ed. New York: Springer-Verlag; 2006. p. 267-300.

24. Saldana J. The coding manual for qualitative researchers. Los Angeles: Sage; 2009.

25. Health Resources and Service Administration. Washington: 2010. [cited 2013 May]. HRSA Office of Rural Health Policy. Meaningful Use and Critical Access Hospitals: a primer on HIT adoption in the rural health care setting. Available from: http://www.hrsa.gov/ruralhealth/pdf/meaningfuluseprimer.pdf.

26. Centers for Medicare \& Medicaid Services. Baltimore: CMS; [cited 2013 March 10]. Stage 1 vs. Stage 2 comparison table for eligible hospitals and CAHs (2012). Available from: http://www.cms.gov/Regu lations-and-Guidance/Legislation/EHRIncentivePrograms/Stage_2.html.

27. Osheroff JK, Kleeberg P, Shank T. Clinical decision support-enabled quality improvement for Meaningful Use. Washington DC: Office of the National Coordinator for HIT Annual Meeting; 2012 Dec 13.

28. Davenport T, Prusak, L. Working knowledge: how organizations manage what they know. Boston, Mass.: Harvard Business School Press; 1998.

29.Davenport TH, Glaser J. Just-in-time delivery comes to knowledge management. Harv Bus Rev 2002; 80(7): 107-111, 126. Epub 2002/07/27. 